\title{
Effects of Nine-Month Lifestyle Intervention on Cardiometabolic Risk Factors: Sex Differences in Obese Individuals
}

\author{
Florent Besnier 1,2,3 ${ }^{(0)}$, Anil Nigam 1,2,3, Martin Juneau 1,2,3, Valérie Guilbeault ${ }^{1}$, Elise Latour ${ }^{1}$ and \\ Mathieu Gayda $1,2,3, *$ (D)
}

1 Preventive Medicine and Physical Activity Centre (ÉPIC), Montreal Heart Institute, Université de Montréal, Montréal, QC H1T 1N6, Canada; florent.besnier@umontreal.ca (F.B.); anil.nigam@icm-mhi.org (A.N.); martin.juneau@icm-mhi.org (M.J.); valerie.guilbeault@icm-mhi.org (V.G.); elise.latour@icm-mhi.org (E.L.)

2 Research Center, Montreal Heart Institute, Université de Montréal, Montréal, QC H1T 1N6, Canada

3 Department of Medicine, Université de Montréal, Montréal, QC H1T 1N6, Canada

* Correspondence: mathieu.gayda@icm-mhi.org; Tel.: +1-(514)-374-1480 (ext. 4208); Fax: +1-(514)-374-2445

Citation: Besnier, F.; Nigam, A.; Juneau, M.; Guilbeault, V.; Latour, E.; Gayda, M. Effects of Nine-Month Lifestyle Intervention on Cardiometabolic Risk Factors: Sex Differences in Obese Individuals. Obesities 2021, 1, 29-35. https:// doi.org/10.3390/Obesities1010003

Academic Editor: Bruno Guigas

Received: 26 January 2021

Accepted: 9 March 2021

Published: 12 March 2021

Publisher's Note: MDPI stays neutral with regard to jurisdictional claims in published maps and institutional affiliations.

Copyright: (c) 2021 by the authors. Licensee MDPI, Basel, Switzerland. This article is an open access article distributed under the terms and conditions of the Creative Commons Attribution (CC BY) license (https:// creativecommons.org/licenses/by/ $4.0 /)$.

\begin{abstract}
Limited data is available on the sex differences and individual responses of cardiometabolic parameters adjusted with potential confounders (i.e. sex, age, baseline values) after a longer term Mediterranean diet (MedD) and high intensity interval training (HIIT) in obese subjects. The objective of this study was to compare the effects of nine-month MedD counseling and supervised HIIT on cardiometabolic risk factors and individual responses in obese women $(n=99)$ and obese men $(n=35)$. Body composition (body mass, fat mass, lean body mass, waist circumference), cardiorespiratory fitness (METs), and cardiometabolic risk factors (blood pressure, blood sample variables) were measured at baseline and after nine months of a program combining MedD and HIIT two to three times a week. When adjusted with sex, age, and baseline values, obese women similarly improved their body composition, METs, and cardiometabolic risk factors vs. obese men. The proportion of responders according to clinical cutoff levels were the same in obese women and men. A longer MedD and HIIT intervention similarly improves body composition, cardiometabolic risk factors, and individual responses in obese women and men, even after adjustment of confounders (sex, age, baseline value).
\end{abstract}

Keywords: lifestyle intervention; Mediterranean diet; high intensity interval exercise training; sex difference; obesity; physical activity

\section{Introduction}

Between 1975 and 2016, the prevalence of obesity in the world nearly tripled, making it the second leading cause of preventable death [1]. Obesity is associated with important comorbidities, such as cardiovascular diseases, type 2 diabetes, stroke, hypertension, osteoarthritis, and certain types of cancer [2]. The Mediterranean diet (MedD) reduces cardiovascular events and is effective for long-term reductions of body mass in overweight/obese subjects [3,4]. Combining MedD to a high intensity interval training (HIIT) showed greater improvement in cardiometabolic parameters vs. MedD alone in adults with metabolic syndrome or obesity [5,6]. Combined lifestyle intervention mostly used caloric restriction diet with moderate intensity aerobic exercise, and sex difference responses in cardiometabolic parameters were poorly studied in obese men vs. women [7]. Limited data is available on the sex differences and individual responses of cardiometabolic parameters adjusted with potential confounders (i.e., sex, age, baseline values) after a longer term MedD and HIIT in obese men and women. We aimed to compare sex differences and individual responses to a nine-month MedD and HIIT program for cardiometabolic risk factors in women and men with obesity. 


\section{Materials and Methods}

\subsection{Patients}

This retrospective study was conducted at the cardiovascular prevention and rehabilitation center (ÉPIC) of the Montreal Heart Institute, and data from a nine-month MedD and supervised HIIT program were analyzed. This clinical program was on a voluntary basis and participants were paying for the program [6]. This study was approved by the Research Ethics and New Technology Development Committee of the Montreal Heart Institute. Data from 99 obese women and 35 obese men were retrospectively analyzed at baseline and at the end of the nine-month intervention. Thus, inclusion criteria at baseline were age $>18$ years and obesity defined as fat mass percentage $>25 \%$ for men and $>35 \%$ for women [6] (see the Inclusion-Exclusion section of the Supplemental Text for details).

\subsection{Measurements}

All participants underwent a complete clinical evaluation, including measurement of height, body mass, waist circumference, body composition (Tanita, model 418C, Tokyo, Japan), blood analysis, resting electrocardiogram, and a symptom-limited maximal exercise treadmill test at baseline and at nine months of program [6] (see the Measurements section of the Supplemental Material Text for details).

\subsection{Lifestyle Intervention Program}

\subsubsection{HIIT and Resistance Training Program}

All participants performed supervised HIIT and resistance training consisting of two to three supervised sessions per week for $60 \mathrm{~min}$ for each session. The intensity of HIIT was prescribed according the estimation of the peak power output from the METs value as previously described [6] (see the HIIT and Resistance Program section of the Supplemental Text for details).

\subsubsection{Mediterranean Diet Counseling Intervention (MedD)}

All participants underwent ten individual meetings with a dietician in our center. We obtained data on eating habits and motivation, and provided the principles of the MedD during the first visit. The aim of this MedD was to meet the Canadian Guidelines (2000-2400 kcal/day), and it was adapted to each participant without severe restriction (see the Mediterranean Diet Nutritional Counselling section of the Supplemental Text for details). Clinically successful responders were defined according to significant clinical cutoff conferring health and/or prognosis benefits in the obese population. Indeed, a $5 \%$ body mass loss is frequently reported to lead to health benefits, while a $5 \mathrm{~cm}$ waist circumference loss is associated to a $9 \%$ reduced relative risk for total mortality $[8,9]$. Furthermore, a $5 \mathrm{~mm} \mathrm{Hg}$ reduction in SBP was chosen, and is associated with a 7\% reduction in total mortality [10]. In addition, a cardiorespiratory fitness (METs) increase of $5 \%$ was chosen as a positive response threshold to aerobic training in inactive men and women [11].

\subsection{Statistical Analysis}

All data are expressed as mean \pm standard deviation (SD) or in a number and percentage. Clinical characteristics, cardiometabolic risk factors, and cardiorespiratory fitness were compared between sex groups using two-way ANOVA (group $\times$ time) with repeated measure (time) (Table 1). A chi squared test was used to compare proportion of responders over women and men (Table 2). A paired student $t$-test was used to compare intragroup changes. A one-way ANCOVA was conducted to compare the effectiveness of the intervention (based on the change between post-intervention and pre-intervention data) in cardiometabolic risk factors on sex while controlling for age and baseline values (Figure 1). Baseline clinical characteristics, cardiometabolic risk factors, and cardiorespiratory fitness were compared between obese women and men using a student $t$-test (Supplementary Materials Table S1). For this, homoscedasticity, normality, and absence of interaction between 
the sex variable and baseline measurement checks were carried out and the assumptions met. All statistical tests were two-sided and conducted at a 0.05 significance level. Statistical analyses were performed with the use of Stata SE 15.1 (StataCorp LP, College Station, TX, USA).
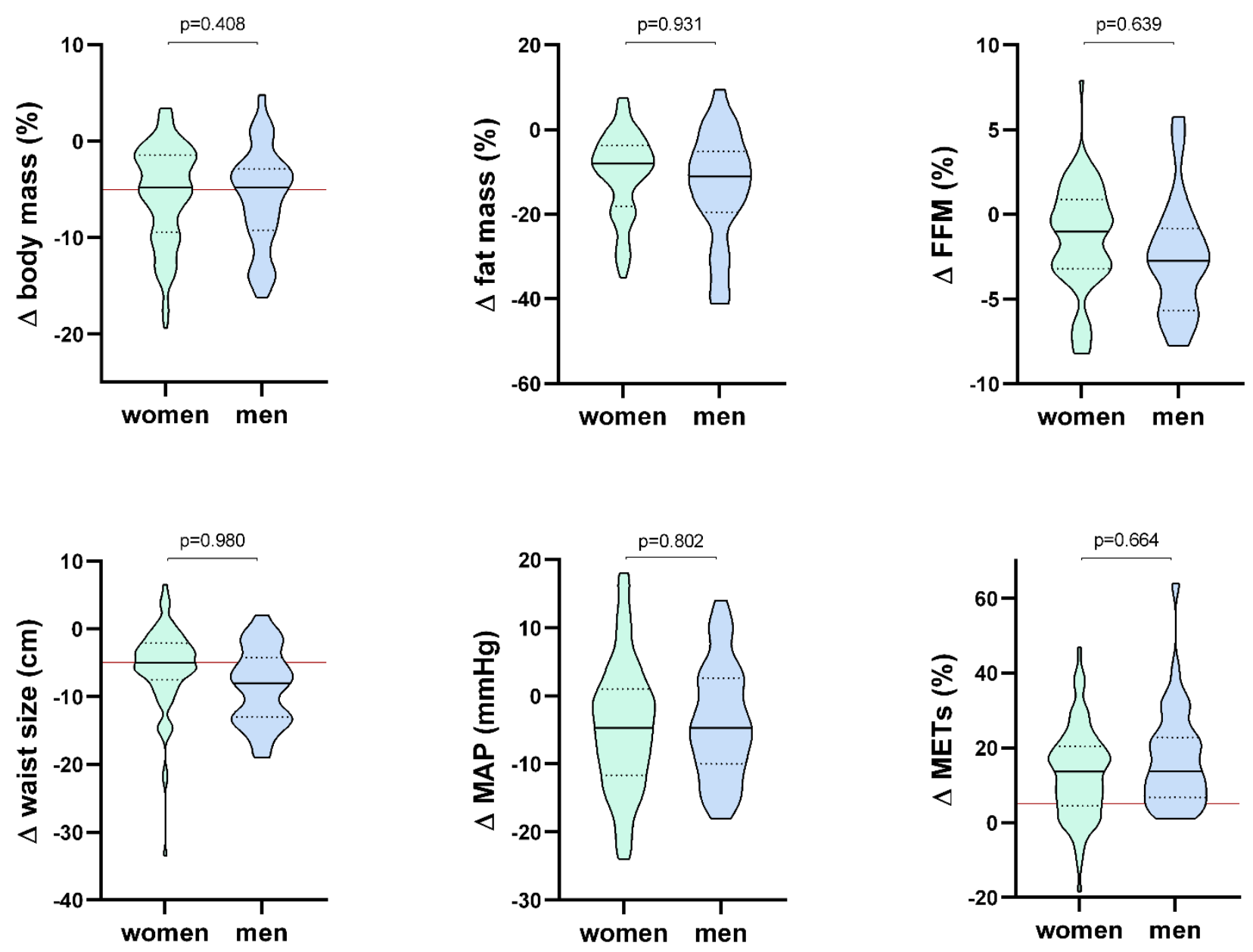

Figure 1. Violin box representing main cardiometabolic risk factors in obese women and men. The continuous black line is the median, the black dotted line is the interquartile range, and the continuous red line represents the clinical responder's cutoff, with adjusted $p$-values (with age, sex, and baseline value) between obese women and men. 
Table 1. Clinical characteristics, cardiometabolic risk factors, and cardiorespiratory fitness before and after the nine-month lifestyle intervention in obese women and men.

\begin{tabular}{|c|c|c|c|c|c|c|c|c|c|}
\hline & \multicolumn{2}{|c|}{ Women $n=99$} & \multicolumn{4}{|c|}{ Men $n=35$} & & & \\
\hline & Pre & Post & & Pre & Post & & \multicolumn{3}{|c|}{ ANOVA } \\
\hline & Mean \pm SD & Mean \pm SD & $p$ & Mean \pm SD & Mean \pm SD & $p$ & Time & Group & Interaction \\
\hline Age (years) & $49.38 \pm 7.53$ & & & $63.17 \pm 4.68$ & & & & & \\
\hline Metabolic Syndrome (\%) * & $42.4 \%$ & & & $42.9 \%$ & & & & & \\
\hline \multicolumn{10}{|l|}{$\begin{array}{l}\text { Anthropometric } \\
\text { characteristics }\end{array}$} \\
\hline Height $(\mathrm{cm})$ & $161.5 \pm 6.17$ & & & $174.6 \pm 6.2$ & & & & & \\
\hline $\mathrm{BMI}\left(\mathrm{kg} / \mathrm{m}^{2}\right)$ & $35.28 \pm 5.19$ & $33.19 \pm 4.98$ & $<0.001$ & $35.95 \pm 5.01$ & $33.89 \pm 4.71$ & $<0.001$ & $<0.001$ & 0.559 & 0.476 \\
\hline Waist size $(\mathrm{cm})$ & $107.71 \pm 11.70$ & $102.03 \pm 11.75$ & $<0.001$ & $120.03 \pm 12.31$ & $108.54 \pm 21.07$ & $<0.001$ & $<0.001$ & $<0.001$ & 0.007 \\
\hline Fat Mass (\%) & $45.16 \pm 4.92$ & $42.64 \pm 5.25$ & $<0.001$ & $33.49 \pm 4.39$ & $31.08 \pm 5.37$ & $<0.001$ & $<0.001$ & $<0.001$ & 0.564 \\
\hline Fat Mass (kg) & $41.92 \pm 10.82$ & $37.06 \pm 9.77$ & $<0.001$ & $37.40 \pm 10.20$ & $32.40 \pm 9.87$ & $<0.001$ & $<0.001$ & 0.015 & 0.242 \\
\hline Fat Free Mass (kg) & $49.75 \pm 5.39$ & $48.63 \pm 5.18$ & $<0.001$ & $72.77 \pm 10.04$ & $70.33 \pm 9.98$ & $<0.001$ & $<0.001$ & $<0.001$ & 0.006 \\
\hline Fat Mass Trunk (\%) & $42.82 \pm 5.20$ & $40.21 \pm 5.59$ & $<0.001$ & $36.09 \pm 3.74$ & $33.69 \pm 5.72$ & $<0.001$ & $<0.001$ & $<0.001$ & 0.691 \\
\hline Fat Mass Trunk (kg) & $21.05 \pm 5.38$ & $18.60 \pm 4.84$ & $<0.001$ & $22.04 \pm 4.87$ & $19.57 \pm 5.78$ & $<0.001$ & $<0.001$ & 0.464 & 0.314 \\
\hline \multicolumn{10}{|l|}{ Blood pressure } \\
\hline $\operatorname{MAP}(\mathrm{mmHg}) *$ & $97.85 \pm 7.97$ & $93.47 \pm 6.96$ & $<0.001$ & $101.89 \pm 7.86$ & $97.58 \pm 6.61$ & 0.014 & $<0.001$ & $<0.001$ & 0.689 \\
\hline \multicolumn{10}{|l|}{ Lipid and glucose profile } \\
\hline Total cholesterol (mmol/L) & $5.04 \pm 0.97$ & $4.87 \pm 0.98$ & 0.060 & $4.98 \pm 1.30$ & $4.71 \pm 1.07$ & 0.109 & 0.027 & 0.669 & 0.825 \\
\hline HDL chol. (mmol/L) & $1.34 \pm 0.32$ & $1.36 \pm 0.30$ & 0.414 & $1.18 \pm 0.27$ & $1.28 \pm 0.33$ & 0.002 & 0.003 & 0.045 & 0.029 \\
\hline LDL chol. (mmol/L) & $3.07 \pm 0.80$ & $2.92 \pm 0.87$ & 0.061 & $3.11 \pm 1.21$ & $2.86 \pm 1.01$ & 0.085 & 0.021 & 0.926 & 0.733 \\
\hline Triglycerides (mmol/L) & $1.40 \pm 0.65$ & $1.28 \pm 0.60$ & 0.046 & $1.52 \pm 0.55$ & $1.29 \pm 0.70$ & 0.030 & 0.004 & 0.464 & 0.412 \\
\hline TG/HDL & $1.16 \pm 0.76$ & $1.03 \pm 0.64$ & 0.011 & $1.38 \pm 0.64$ & $1.15 \pm 0.91$ & 0.056 & 0.002 & 0.179 & 0.538 \\
\hline Glycemia (mmol/L) & $5.42 \pm 0.92$ & $5.18 \pm 0.65$ & 0.002 & $5.63 \pm 1.04$ & $5.38 \pm 0.52$ & 0.233 & 0.008 & 0.094 & 0.651 \\
\hline \multicolumn{10}{|l|}{ Cardiorespiratory fitness } \\
\hline METs & $8.06 \pm 1.37$ & $9.15 \pm 1.43$ & $<0.001$ & $9.19 \pm 1.80$ & $10.72 \pm 2.09$ & $<0.001$ & $<0.001$ & $<0.001$ & 0.016 \\
\hline $\begin{array}{c}\dot{V} \mathrm{O}_{2 \text { peak }}(\mathrm{mL} / \mathrm{min} / \mathrm{kg} \\
\mathrm{FFM})\end{array}$ & $51.08 \pm 7.35$ & $56.46 \pm 6.91$ & $<0.001$ & $48.35 \pm 8.55$ & $54.44 \pm 7.93$ & $<0.001$ & $<0.001$ & 0.067 & 0.987 \\
\hline
\end{tabular}


Table 2. Proportion of responders (in \%) after the nine-month lifestyle intervention in obese women and men according to the cutoffs defined (see Materials and Methods section).

\begin{tabular}{cccc}
\hline $\begin{array}{c}\text { Proportion of Responders (\%) } \\
\text { Regarding Defined Cutoff }\end{array}$ & Women & Men & $p$-Value \\
\hline METs improvement $>5 \%$ & $73.8 \%$ & $81.8 \%$ & 0.414 \\
Body mass loss $>5 \%$ & $46.7 \%$ & $48.5 \%$ & 0.902 \\
Waist size reduction $>5 \mathrm{~cm}$ & $45.5 \%$ & $68.6 \%$ & 0.067 \\
SBP reduction $>5 \mathrm{~mm} \mathrm{Hg}$ & $57.3 \%$ & $54.3 \%$ & 0.821 \\
\hline
\end{tabular}

\section{Results}

Women were significantly younger compared to men $(p<0.001)$ (Table 1$)$. Clinical characteristics, cardiometabolic riks factors, and cardiorespiratory fitness before and after the nine-month lifestyle intervention in obese women and men are presented in Table 1. The proportion of metabolic syndrome is comparable between men and women $(42 \%$ for each group, $p=0.964$ ). After the intervention, both groups significantly improved cardiorespiratory fitness, body composition, and arterial blood pressure.

The proportion of responders according to clinical cutoff levels were the same in the two groups (Table 2).

The individual changes in cardiorespiratory fitness (METs), mean arterial blood pressure, body mass, fat mass, waist size, and fat-free mass (adjusted for sex, age, and baseline values) are presented in Figure 1 (violin box).

\section{Discussion}

The main findings of this study were that: (1) a lifestyle intervention combining MedD and HIIT was as effective in the improvement of certain main cardiometabolic risk factors (body and fat mass, blood pressure, triglycerides, glycemia, normalized $\dot{V} \mathrm{O}_{2}$ peak) in obese women as it was in men. (2) In addition, when adjust with potential confounders (age, sex, and baseline values) that influence most baseline values, our lifestyle intervention (HIIT and MedD) similarly improved cardiometabolic risk factors (body mass, fat mass, free fat mass, waist size, blood pressure, METs) in obese women and men. (3) The prevalence of clinical responders (in \%) to the intervention was similar in obese women and men. The originality of our work is in the sex comparison of the effects of combining MedD and HIIT (nine months) on cardiometabolic risk factor parameters in obese women and men, which has not been studied previously. In particular, individual response and responder proportion (according to clinical cutoff) of obese men and women after this lifestyle intervention has not been studied. In addition, we have taken into account the initial potential confounders between women and men (age, sex, and baseline values of body composition).

Previous intervention studies on sex differences in body composition changes have used a caloric restriction diet with physical activity (either recommended or supervised), with various durations (four to 18 months) [7]. Most of the studies were performed in overweight adults [7,12-17], and three in obese adults [18-20]. Overweight men generally lose more weight (in absolute value) vs. women after these interventions [11-16], due to their higher initial values [7,12]. When expressed in \%, a higher [12,17] or similar loss [15] was reported for body mass and fat mass in overweight or obese men vs. women. Obese men can either lose more body and fat mass (global, regional in $\mathrm{kg}$ ) [20] or a similar amount vs. women after these interventions [19]. Our results on fat mass agree with the last cited study [19] in obese subjects, with no sex differences in adiposity reduction (subcutaneous and visceral) after diet and exercise. Men generally have more lean body mass and women more fat mass proportionally. Regionally, men accumulate more fat mass in the abdomen area and women more in the hips and thighs [21], putting men at a higher cardiometabolic risk. Regarding blood pressure and fitness, obese women and men responded similarly to our intervention, in agreement with previous studies [6,12,22]. 
Our study has some limitations, as it was not designed to compare the sex differences, and our groups were not of equal number, with a larger number of obese women than men. Our observational retrospective design had no sedentary control group. Furthermore, data on adherence to the Mediterranean diet was not collected, and therefore, the contribution of diet and/or exercise to cardiometabolic risk factor improvement cannot be addressed. However, the exercise adherence was shown to be around three sessions/week, which is quite a modest dose of exercise training [6]. The participants were mostly women that paid for this lifestyle program, and were probably more motivated and had a higher socioeconomic status compared to the general obese population. In conclusion, a longer MedD and HIIT intervention similarly improves body composition, cardiometabolic risk factors, and individual responses to clinical cutoff in obese women and men, even after adjustment of confounders (sex, age, baseline value).

Supplementary Materials: The following are available online at https:/ /www.mdpi.com/2673-416 8/1/1/3/s1: Supplementary Text 1 and Table S1.

Author Contributions: Conceptualization, F.B., A.N., M.J., V.G., E.L. and M.G.; methodology, F.B., A.N., M.J. and M.G.; software, F.B. and M.G.; validation, F.B., A.N., M.J. and M.G.; formal analysis, F.B. and M.G.; investigation, F.B., A.N., M.J., V.G., E.L. and M.G.; resources, F.B., A.N., M.J., V.G., E.L. and M.G.; data curation, F.B., A.N., M.J. and M.G.; writing-original draft preparation, F.B. and M.G.; writing—review and editing, F.B., A.N., M.J. and M.G.; project administration, A.N., M.J., V.G., E.L. and M.G.; funding acquisition, A.N. and M.J. All authors have read and agreed to the published version of the manuscript.

Funding: This research was funded by the ÉPIC Foundation, Montreal Heart Institute Foundation. Florent Besnier is funded by Mirella and Lino Saputo Research Chair in cardiovascular diseases and the prevention of cognitive decline from Université de Montréal at the Montreal Heart Institute.

Institutional Review Board Statement: The study was conducted according to the guidelines of the Declaration of Helsinki, and approved by the Research Ethics and New Technology Development Committee of the Montreal Heart Institute (No. Projet Kilo-Acif: 2014-1569).

Informed Consent Statement: Patient consent was not applicable because of the retrospective nature of the studies and anonymous data originated from the clinical program. According to the Institutional Review Board policy of the Montreal Heart Institute concerning retrospective studies, the present study was approved by the Medical Director of the Montreal Heart Institute.

Data Availability Statement: Data available on request due to restrictions e.g., privacy or ethical. The data presented in this study are available on request from the corresponding author.

Conflicts of Interest: The authors declare no conflict of interest. The funders had no role in the design of the study; in the collection, analyses, or interpretation of data; in the writing of the manuscript, or in the decision to publish the results.

\section{References}

1. Hodgson, C.; Corscadden, L.; Taylor, A.; Sebold, A.; Pearson, C.; Kwan, A.; Sommerer, S.; Halley, R.L.; Walsh, P.; Shane, A.; et al. Obesity in Canada: A Joint Report from the Public Health Agency of Canada and the Canadian Institute for Health Information; Canadian Institute for Health Information: Ottawa, ON, Canada, 2011; Volume 62.

2. Nguyen, T.; Lau, D.C. The obesity epidemic and its impact on hypertension. Can. J. Cardiol. 2012, 28, 326-333. [CrossRef]

3. Estruch, R.; Ros, E.; Salas-Salvadó, J.; Covas, M.-I.; Corella, D.; Arós, F.; Gómez-Gracia, E.; Ruiz-Gutiérrez, V.; Fiol, M.; Lapetra, J.; et al. Primary Prevention of Cardiovascular Disease with a Mediterranean Diet. N. Engl. J. Med. 2013, 368, 1279-1290. [CrossRef] [PubMed]

4. Shai, I.; Schwarzfuchs, D.; Henkin, Y.; Shahar, D.R.; Witkow, S.; Greenberg, I.; Golan, R.; Fraser, D.; Bolotin, A.; Vardi, H.; et al. Weight Loss with a Low-Carbohydrate, Mediterranean, or Low-Fat Diet. N. Engl. J. Med. 2008, 359, 229-241. [CrossRef] [PubMed]

5. Landaeta-Díaz, L.; Fernández, J.M.; Silva-Grigoletto, M.D.; Rosado-Alvarez, D.; Gómez-Garduño, A.; Gómez-Delgado, F.; LópezMiranda, J.; Pérez-Jiménez, F.; Fuentes-Jiménez, F. Mediterranean diet, moderate-to-high intensity training, and health-related quality of life in adults with metabolic syndrome. Eur. J. Prev. Cardiol. 2013, 20, 555-564. [CrossRef]

6. Dalzill, C.; Nigam, A.; Juneau, M.; Guilbeault, V.; Latour, E.; Mauriège, P.; Gayda, M. Intensive Lifestyle Intervention Improves Cardiometabolic and Exercise Parameters in Metabolically Healthy Obese and Metabolically Unhealthy Obese Individuals. Can. J. Cardiol. 2014, 30, 434-440. [CrossRef] 
7. Williams, R.L.; Wood, L.G.; Collins, C.E.; Callister, R. Effectiveness of weight loss interventions-Is there a difference between men and women: A systematic review. Obes. Rev. 2014, 16, 171-186. [CrossRef]

8. Berentzen, T.L.; Jakobsen, M.U.; Halkjaer, J.; Tjønneland, A.; Overvad, K.; Sørensen, T.I.A. Changes in Waist Circumference and Mortality in Middle-Aged Men and Women. PLoS ONE 2010, 5, e13097. [CrossRef] [PubMed]

9. Blackburn, G.L. Benefits of weight loss in the treatment of obesity. Am. J. Clin. Nutr. 1999, 69, 347-349. [CrossRef] [PubMed]

10. Stamler, R. Implications of the INTERSALT study. Hypertension 1991, 17, I16. [CrossRef] [PubMed]

11. Byrd, B.R.; Keith, J.; Keeling, S.M.; Weatherwax, R.M.; Nolan, P.B.; Ramos, J.S.; Dalleck, L.C. Personalized Moderate-Intensity Exercise Training Combined with High-Intensity Interval Training Enhances Training Responsiveness. Int. J. Environ. Res. Public Health 2019, 16, 2088. [CrossRef]

12. Stevens, V.J.; Corrigan, S.A.; Obarzanek, E.; Bernauer, E.; Cook, N.R.; Hebert, P.; Mattfeldt-Beman, M.; Oberman, A.; Sugars, C.; Dalcin, A.T.; et al. Weight Loss Intervention in Phase 1 of the Trials of Hypertension Prevention. Arch. Intern. Med. 1993, 153, 849-858. [CrossRef] [PubMed]

13. Tate, D.F.; Jeffery, R.W.; Sherwood, N.E.; Wing, R.R. Long-term weight losses associated with prescription of higher physical activity goals. Are higher levels of physical activity protective against weight regain? Am. J. Clin. Nutr. 2007, 85, 954-959. [CrossRef] [PubMed]

14. Andersen, R.E.; Franckowiak, S.C.; Bartlett, S.J.; Fontaine, K.R. Physiologic changes after diet combined with structured aerobic exercise or lifestyle activity. Metabolism 2002, 51, 1528-1533. [CrossRef]

15. Evans, E.M.; Mojtahedi, M.C.; Thorpe, M.P.; Valentine, R.J.; Kris-Etherton, P.M.; Layman, D.K. Effects of protein intake and gender on body composition changes: A randomized clinical weight loss trial. Nutr. Metab. 2012, 9, 55. [CrossRef]

16. West, D.S.; Prewitt, T.E.; Bursac, Z.; Felix, H.C. Weight Loss of Black, White, and Hispanic Men and Women in the Diabetes Prevention Program. Obesity 2008, 16, 1413-1420. [CrossRef]

17. Wing, R.R.; Jeffery, R.W. Effect of modest weight loss on changes in cardiovascular risk factors: Are there differences between men and women or between weight loss and maintenance? Int. J. Obes. Relat. Metab. Disord. J. Int. Assoc. Study Obes. 1995, 19, 67-73.

18. Luscombe-Marsh, N.D.; Noakes, M.; Wittert, G.A.; Keogh, J.B.; Foster, P.; Clifton, P.M. Carbohydrate-restricted diets high in either monounsaturated fat or protein are equally effective at promoting fat loss and improving blood lipids. Am. J. Clin. Nutr. 2005, 81, 762-772. [CrossRef]

19. Janssen, I.; Ross, R. Effects of sex on the change in visceral, subcutaneous adipose tissue and skeletal muscle in response to weight loss. Int. J. Obes. 1999, 23, 1035-1046. [CrossRef]

20. Straznicky, N.E.; Lambert, E.A.; Nestel, P.J.; McGrane, M.T.; Dawood, T.; Schlaich, M.P.; Masuo, K.; Eikelis, N.; De Courten, B.; Mariani, J.A.; et al. Sympathetic Neural Adaptation to Hypocaloric Diet with or without Exercise Training in Obese Metabolic Syndrome Subjects. Diabetes 2009, 59, 71-79. [CrossRef]

21. Bredella, M.A. Sex Differences in Body Composition. Sex Gend. Factors Affect. Metab. Homeost. Diabetes Obes. $2017,1043,9-27$.

22. Chrøis, K.M.; Dohlmann, T.L.; Søgaard, D.; Hansen, C.V.; Dela, F.; Helge, J.W.; Larsen, S. Mitochondrial adaptations to high intensity interval training in older females and males. Eur. J. Sport Sci. 2020, 20, 135-145. [CrossRef] [PubMed] 